\title{
Gender, Development, Values, Adaptation, and Discrimination in Acculturating Adolescents: The Case of Turk Heritage Youth Born and Living in Belgium
}

\author{
Derya Güngör • Marc H. Bornstein
}

Published online: 31 August 2008

(C) The Author(s) 2008. This article is published with open access at Springerlink.com

\begin{abstract}
This study addressed gender differences and similarities in acculturation, values, adaptation, and perceived discrimination among middle (14-17 years) and late (1820 years) adolescents. Girls perceived less discrimination and showed better adaptation than did boys. All adolescents valued openness to change and self-transcendence similarly, but older adolescents attached greater importance to their heritage culture and conservatism. Overall, a larger gender gap in acculturation experiences emerged in late adolescence. The findings are discussed with reference to acculturative and developmental processes in a multicultural context.
\end{abstract}

Keywords Immigrants $\cdot$ Adolescents $\cdot$ Gender .

Acculturation $\cdot$ Adaptation $\cdot$ Perceived discrimination

\section{Introduction}

Acculturation and Adolescence

Acculturation is a complex and dynamic process that involves many psychological and cultural changes that take

D. Güngör $(\bowtie)$

Child and Family Research, Eunice Kennedy Shriver National Institute of Child Health and Human Development,

National Institutes of Health,

6705 Rockledge Drive, Suite 8030,

Bethesda, MD 20892-7971, USA

e-mail: D.Gungor1@uu.nl

D. Güngör

Utrecht University,

Utrecht, The Netherlands

\section{H. Bornstein}

Department of Health and Human Services,

Eunice Kennedy Shriver National Institute of Child Health

and Human Development, National Institutes of Health,

Bethesda, MD, USA place in an intercultural context (Berry 2003; Lansford et al. 2007). Because of its complexity, distinguishing different aspects of the acculturation experience is desirable (Phinney 2006). For example, gender is a central organizing factor of migrant life. Transnational migration impacts men and women differently, and it modifies relations between them. However, the ways in which transnational migration is gendered is an area that has received insufficient attention (Pessar and Mahler 2003; Suárez-Orozco and Qin 2006). In this study, we focus on the role of gender in adolescent acculturation, and we fit this research into a tripartite organization to acculturation of values, adaptation, and discrimination.

Acculturation is about change, and adolescence is time of constant self re-definition and re-evaluation of relationships with others. That said, only a limited number of studies have paid special attention to acculturative changes through adolescence (e.g., Fuligni 2001; Phinney 1989; Schönpflug 2001). To begin to fill this gap, we investigated several dimensions of acculturation in relation to gender in middle and late adolescence. Studying acculturation in adolescents is important for at least two reasons. First, as a transmission and transformation process, acculturation is often accompanied by psychological distress (Berry 1997). Adolescence, too, is a time of identity formation during which adolescents search for answers to such questions as "who am I?". Acculturation can be particularly stressful for minority adolescents who have to navigate between the conflicting demands of two cultures. This, in turn, may add to the stress of the developmental tasks of adolescence and undermine healthy identity development (Phinney 1990). Among Turk immigrant adolescents, for example, and especially among those who overemphasize ethnic identity and heritage culture, problem behavior is more common and a fragile/defensive identity development is more likely (Lange 1990; Sam 2000; Simila 1987). Second, the 
majority of the immigrant population in Western Europe is today younger than 30 . This implies major demographic transitions in the next decades. In addition, younger generation immigrants are exposed more to mainstream cultures (e.g., via schools). Therefore, investigating the way adolescents in immigrant families experience acculturation and intercultural relations with a focus on gender is important for developing social policies aimed at fostering positive development and successful futures for children of immigrants as well as cohesion in society at large (Hernandez et al. 2008; Motti-Stefanidi 2008). This study focuses on second-generation immigrant youth of Turk heritage families with a relatively collectivist background but who were born, educated, and live in Belgium, a more individualist Western society.

Psychological acculturation research follows a scheme that includes acculturation conditions, acculturation orientations, and acculturation outcomes (Arends-Tóth and Van de Vijver 2006). Acculturation conditions, which refer to the contexts of acculturation, have a major impact on acculturation. At the individual level, acculturation conditions refer to changes over time (e.g., age, length of settlement, generational differences), position in the society, personality characteristics (e.g., social norms, coping strategies), and situational or social context (e.g., social support, stress). At the group level, acculturation conditions involve the type of migration (e.g., temporary versus permanent, voluntary versus involuntary), characteristics of the society of origin (e.g., collectivist, individualist), characteristics of the immigrant group (e.g., ethnic vitality, social attachment), characteristics of the host society (e.g., cultural openness, discrimination, views on immigrants in general), and intergroup relationships (e.g., social inequality, social distance).

Important to understand for the process of acculturation are both the historical and attitudinal situations faced by immigrants. Some societies accept cultural pluralism resulting from immigration and support cultural diversity as a shared communal resource; this positive multicultural ideology corresponds to an expectation that integration will be the appropriate strategy for cultural communities to engage one another (Berry and Kalin 1995). Other societies eliminate diversity through policies and programs of assimilation, and still other societies foster the segregation or marginalization of their immigrant populations. Even where pluralism prevails, there are well-known variations in the relative acceptance of specific cultural, racial, and religious groups (Berry and Kalin 1995; Lebedeva and Tartarko 2004). Members of groups that are less wellaccepted often experience hostility, rejection, and discrimination, factors that are predictive of poor self-esteem, psychological health, and long-term adaptation (Berry 1997; Berry et al. 2006; Jasinskaja-Lahti and Liebkind
2001; Moghaddam et al. 1990). Many immigrants might not have experienced discrimination personally, but they may still be aware of negative attitudes and behaviors directed at their group, and, therefore, it is useful to distinguish between perceptions of person- and group-level discrimination (Taylor et al. 1990). Although it is stressful and has negative health outcomes, the perception of discrimination against the in-group can increase the likelihood of ethnic identification (see Dion 2001) and collective action (Gurr and Harff 1994). In this study, we assessed both personal and group discrimination perceived by Turk adolescents living in Belgium.

Regarding the impact of Turks' perceptions of exclusion and discrimination on their psychological adaptation, research to date does not provide a clear picture. Virta et al. (2004) compared the level of psychological well-being among Turk-heritage adolescents in Norway and Sweden and reported that Turks in Sweden showed better adaptation than Turks in Norway. Poorer adaptation of Turks in Norway was attributed in part to a higher degree of perceived discrimination. Vedder et al. (2007) documented that for Turk adolescents living in Norway, Sweden, Finland, Germany, France, and the Netherlands perceived discrimination was the strongest negative predictor of wellbeing and sociocultural adaptation. In other studies, Turk migrants reported that they experienced more discrimination but lower psychological distress than other migrant groups (Liebkind and Jasinskaja-Lahti 2000).

Acculturation orientations refer to how immigrants combine (or do not combine) their cultures of origin and destination. Orientations are critical to understanding the acculturation process (e.g., Berry 1980; Ward et al. 2001) because they link antecedent conditions to outcomes. Immigrants may prioritize their culture of origin, isolating themselves from their new culture of destination. This "separation" strategy maintains the minority culture and rejects the majority culture. As a direct alternative, immigrants may relinquish their culture of origin and completely embrace their culture of destination; a strategy called "assimilation." These two whole cloth options are complemented by two others. In one, immigrants "integrate" their original culture with their new one, making the best of both worlds. Finally, immigrants might neither maintain their culture of origin nor adopt their culture of destination, consequently "marginalizing" themselves by rejecting both. These different paths are empirically, as well as conceptually, independent (e.g., Ryder et al. 2000). Berry et al. (2006) studied over 5,000 immigrant youth who settled in 13 countries (including Turk youth in Western Europe) and assessed a number of variables (including attitudes toward the four ways of acculturating, ethnic and national identities, language knowledge and use, and friends). Four distinct acculturation profiles emerged from 
a cluster analysis of their attitudinal and behavioral data. The largest number of youth fell into the integrated cluster; the second largest cluster opted for separation; the third preferred assimilation; finally, a diffuse cluster emerged that resembled marginalization. Integration, the combination of cultural adaptation and maintenance, is the acculturation strategy most preferred and practiced by immigrants (e.g., Berry and Sam 1997; Van Oudenhoven et al. 1996).

The original four-fold model of acculturation (e.g., Berry 1980) assumed that acculturation strategies have trait characteristics; that is, an immigrant who prefers integration is believed to prefer this strategy across all domains of life. The validity of the assumption of cross-domain stability has been questioned, however (Arends-Tóth and Van de Vijver 2003; Phalet and Swyngedouw 2004), and models of acculturation orientations now focus on domain specificity. Domain-specific models are based on the assumption that an immigrant's preference for one or another acculturation orientation can (and often will) vary across life domains. Two major domains are public and private. The public domain involves activities aimed at participation (broadly defined) in the social life of both majority and minority groups. The private domain involves more personal, valuerelated matters (Arends-Tóth and van de Vijver 2003). Examples of the public domain include social contacts, following the news, and language use; examples of the private domain include celebrations and childrearing. Often cultural adaptation (integration) is preferred in the public domain, and cultural maintenance (separation) in the private domain. In brief, change may be required to fit into and function effectively in the mainstream society, whereas practices in the home may not need to change. For example, Phalet and Swyngedouw (2004) reported that Turk minorities in the Netherlands attribute more importance to cultural maintenance in the home and family context (private domain), whereas the adaptation dimension is more important in school and work situations (public domain). Hence, psychological acculturation does not affect all aspects of life identically. Accordingly, we asked questions about acculturation in both the private and public domains from Turk girls and boys in Belgium.

Acculturation outcomes are usually divided into psychological well-being and sociocultural adaptation (Ward and Kennedy 1994). Psychological adjustment includes subjective well-being, self-esteem, and psychological health. Sociocultural adaptation is related to learning processes and involves the acquisition of effective behaviors, social skills, language mastery, and cultural knowledge. Psychological and sociocultural adjustment may be related, but are predicted by different factors and show different patterns over time (i.e., sociocultural problems steadily decrease, whereas psychological distress may increase and decrease). In line with this distinction, we assessed psychological adaptation in terms of self-esteem and the level of symptomology, and sociocultural adaptation, in terms of the degree of difficulty experienced in various areas of daily life by female and male Turk youth in Belgium.

Beyond culture maintenance or adaptation in private and public, and level of adaptation psychologically and socioculturally, we were interested in how acculturation might differentially affect a central feature of adolescence by gender: values. Values are defined as desirable, transsituational goals that vary in importance and serve as guiding principles in people's lives (Schwartz 1992). Based on 210 samples from 67 countries (including Turkey and Belgium), Schwartz (1992; Schwartz and Bilsky 1990) identified ten motivationally distinct, basic values: Power (social status and prestige, control or dominance over people and resources), Achievement (personal success through demonstrating competence according to social standards), Hedonism (pleasure and sensuous gratification for oneself), Stimulation (excitement, novelty, and challenge in life), Self-direction (independent thought and action-choosing, creating, exploring), Universalism (understanding, appreciation, tolerance and protection for the welfare of all people and for nature), Benevolence (preservation and enhancement of the welfare of people with whom one is in frequent personal contact), Tradition (respect, commitment and acceptance of the customs and ideas that traditional culture or religion provide the self), Conformity (restraint of actions, inclinations, and impulses likely to upset or harm others and violate social expectations or norms), and Security (safety, harmony, and stability of society, or relationships, and of self). Schwartz (1992, 1994) subsequently argued that because the ten values form a motivational continuum, thus the array of value items forms indexes of broader 'value orientations', one can simplify the value structure. The most commonly applied modification of the value structure has been to use four higher-order value types (e.g., Hrubes et al. 2001; Ros et al. 1999): Self-enhancement values (power, achievement) emphasize self-interest, social status, and prestige; Selftranscendence values (universalism, benevolence) emphasize concern for the welfare and interests of others; Openness to change values (self-direction, stimulation, hedonism) emphasize independent action, thought, and feeling and readiness for new experience; and Conservatism values (security, conformity, tradition) emphasize selfrestriction, order, and resistance to change. Accordingly, we adopted this framework in our analyses.

\section{Turks in Belgium and Western Europe}

Turks constitute one of the largest immigrant groups in Belgium. The first Turk migrants arrived in Belgium as "guest workers" in 1960s under dual agreements of the two 
national governments. Family reunion laws in the 1970s and relatively poorer economic conditions in Turkey combined to encourage many migrants to settle permanently in Belgium (Abadan-Unat 2002). Turk migrants in Belgium, as in other Western European countries, are among the most disadvantaged members of society in terms of education, affluence, and employment (Tielens 2005; Verhoeven 2000). We studied second generation adolescents (children born in Belgium with at least one parent born in Turkey; Hernandez and Charney 1998). The second generation comprises more than one-third of the Turk Belgian population and is better educated and more upwardly mobile than their parents. However, their positions in terms of education and occupation are still much weaker and manifestly less stable than for Belgians (Verhoeven 2000; Van Damme et al. 2001). In many Western European countries, such as Belgium, Turk immigrants are among the least favored minority group by members of the mainstream society (Hagendoorn 1995; Verkuyten and Kinket 2000), and Turk adolescents perceive more personal and group discrimination as compared to other ethnic groups (Liebkind and Jasinskaja-Lahti 2000; Verkuyten 2002). In general, psychological adaptation is high but sociocultural adaptation is a challenging task for migrant Turk youth (Sam 2000; Smila 1987). Turk migrants rely on their ethnic group to cope with acculturation stress and to move ahead in the mainstream society (Güngör 2007; Phalet and Swyngedouw 2004; Verkuyten 2002).

\section{Gender and Migrant Turk Families in Europe}

In international immigration, immigrant girls and boys often experience acculturation differently, resulting in a gender gap in acculturation strategies, stressors, and adaptation. Evidence from ethnographic, sociological, and psychological research alike suggests that girls in Turk migrant families in Western Europe (e.g., Belgium) are more open to intercultural contact, have greater aspirations for achievement, and possess less conservative gender role attitudes than do boys (e.g., Timmerman 2000; Idema and Phalet 2007; Phalet and Swyngedouw 2004). Idema and Phalet (2007) examined the degree to which adolescents' gender role values resembled or diverged from their samesex parents in Turk migrant families in Germany. They found no difference between values of mothers and fathers, but a significant difference in gender role values of their daughters and sons. The acculturative change was towards more egalitarian gender role values in girls, but not in boys. Turk German adolescent girls' values were more egalitarian than those of their mothers, but the values of adolescent boys were not less conservative than those of their fathers. Phalet and Schönpflug (2001a) reported higher conformity pressure on sons in Turk immigrant families in Germany, probably because traditional familial values prescribe that boys care for their aged parents (Kagitcibasi 1970). In their cross-national study of Turk migrant families in the Netherlands and Germany, Phalet and Schönpflug (2001b) reported that mothers are less aspiring of achievement for daughters and exert less conformity pressure on daughters than on sons, but daughters themselves are not less aspiring than sons.

Women's shift from traditional or conservative gender role attitudes towards more egalitarian ones can be seen as reflecting their greater willingness to participate in public life and share responsibility with men in private life, and reciprocally greater acceptance of the mainstream culture. Phalet and Haker (2004) examined acculturative change in a large-scale random sample of Turk immigrant families in the Netherlands. They reported a normative shift away from conservatism (i.e., decreased emphasis on family obligations, respect for parental authority, and traditional gender roles) from older to younger generations, but young women were significantly less conservative than young men in their gender role values. They preferred to marry and have their first child at a later age and to have fewer children than did men. In their attitudes towards family obligations and parental authority, however, women did not differ from men. In addition, there was no evidence of a gender difference in relatedness, as measured by the value of closeness, contact, and support among family members. It seems that young immigrant women tend to maintain most of the values of their heritage culture in their private life, similar to their male counterparts, but only to the extent that those values do not restrict them to traditional roles as women.

When it comes to psychological adaptation, girls and boys seem to function equally well. Although boys tend to experience more discrimination than girls, they do not report more psychological stress (Liebkind and Jasinskaja-Lahti 2000; Sam et al. 2006), presumably because of boys' higher collectivism and family support (Phalet and Schönpflug 2001b; Verkuyten 2002). Greater emotional support of parents for sons than for daughters is common in traditional collectivist families due to the old-age security value of sons (Kağıtçıbașı 2007).

\section{This Study}

In overview, the present study examines the roles of gender and development in the acculturation, values, adaptation, and perceived discrimination of acculturating younger and older adolescents. Age-related patterns constituted the exploratory part of the study. Drawing on the findings of acculturation conditions, orientations, and outcomes among Turk immigrant youth in Western Europe, we tested the following gender-related hypotheses: (1) Immigrant girls 
would show higher acculturation than immigrant boys towards the mainstream culture in both private and public domains. Girls and boys were not expected to differ in terms of culture maintenance in private and public domains. (2) Girls would show better sociocultural adaptation than boys, but girls and boys were not expected to differ in psychological adaptation. (3) Girls would value openness to change, whereas boys would value conservatism. Boys and girls were not expected to differ in terms of the degree of importance attached to self-enhancement and universalism values. (4) Boys would perceive higher discrimination than girls both at person and group levels.

\section{Method}

\section{Participants}

Altogether 199 second-generation (born in Belgium) Turk Belgian adolescents (96 girls) provided data. Adolescents were recruited from high schools and neighborhoods in the Dutch-speaking part of Belgium (Flanders) where the concentration of Turk immigrant families is high. Adolescents with parents who were both born in Turkey were in the majority ( $89 \%$ ), followed by those with Belgian-born mothers and Turkey-born fathers $(6 \%)$ and then those with Turkey-born mothers and Belgium-born fathers (5\%). There were no significant differences among these three groups of adolescents in terms of the dependent variables of the study, as revealed by one-way ANOVAs. We studied second-generation Turks because they are the most populous and having all participants the same generation level brings a degree of homogeneity to the sampling. Ninety percent of the participants were living in households where both parents were present, $9 \%$ were living either with mother or father only, and $1 \%$ were living with neither (two participants did not respond). Again, these three groups did not differ significantly on the dependent variables. Adolescents reported the highest education level their mothers and fathers had attained $(1=$ no formal education, $2=$ some primary school but not finished, 3=primary school, 4= elementary school, 5=high school, 6=university). Mean level of education was 3.42 for mothers $(S D=1.29)$ and 3.89 for fathers $(S D=1.19)$.

Girls averaged 17.69 years $(S D=1.67$, range $=14-20)$, and boys 17.88 years $(S D=1.77$, range $=14-20), t(197)=$ $-.80, n s$. For the purposes of this report, we divided the samples into middle (14-17 years) and late adolescents (18-20 years), resulting in four groups, middle adolescent girls ( $n=39, M=16.05, S D=1.23)$, late adolescent girls $(n=$ $57, M=18.81, S D=.74)$, middle adolescent boys $(n=37, M=$ $15.89, S D=1.17)$, and late adolescent boys $(n=66, M=19$, $S D=.78)$.
Procedure

Data were collected by a team supervised by the first author. Administration of the measures took place during school sessions, home visits, or visits to after-school youth organizations. Completion of the measures took about $45 \mathrm{~min}$.

\section{Instruments}

All instruments were administered in Dutch. Any instruments originally written in another language were forwardtranslated into Dutch by a Belgian bilingual language teacher and independently back-translated by another teacher (Brislin 1980, 1986). The source and target scales were then compared by a multilingual psychologist, and minor revisions were made to adjust the content and meaning. The instruments were then administered to small groups of adolescents similar to the target group in a pilot study. Final versions were obtained after appropriate revisions in instructions and wording. Adolescents' proficiency in Dutch was measured by asking them to indicate on a four-point scale how well they think they speak Dutch $(1=$ not good at all, $4=$ very good). A significant gender difference emerged: as has been found in many language assessments (e.g., Bornstein et al. 2004), girls self-reported higher language proficiency $(M=3.48, S D=.52)$ than did boys $(M=3.33$, $S D=.51), F(1,190)=4.18, p<.05, \eta^{2}=.02$. There was also a significant main effect of age: Not surprisingly, older adolescents $(M=3.44, S D=.52)$ reported greater proficiency than younger adolescents $(M=3.34, S D=.50), F(1,190)=$ 2.02, $p<.05, \eta^{2}=.01$. Nonetheless, the means of language proficiency for all groups were well above 3 .

\section{Acculturation}

Domain-specific acculturation orientations (i.e., the degrees of culture of origin maintenance and adaptation to the culture of destination in private and public domains) were assessed by single-item measures devised by Phalet and Swyngedouw (2004). Adolescents indicated on five-point scales $(1=$ not important at all, 5=extremely important $)$ how important it was to them to maintain their heritage culture in their family life (private culture maintenance) and outside the family (public culture maintenance) and next how important it was to them to adapt to Belgian culture in their family life (private cultural adaptation) and outside the family (public cultural adaptation).

\section{Psychological Adaptation}

We assessed self-esteem and symptomology. Self-esteem was assessed by Rosenberg's (1965) 10-item Self-Esteem Inventory. Participants responded to a Dutch version of the 
scale that had been used in previous studies (e.g., Arrindell et al. 1999). Ratings on each item ranged between 1 (fully disagree) and 5 (fully agree). Internal reliability $(\alpha)$ of the scale was high (.84). Symptomology was measured by the composite scores of the three subscales of The Brief Symptom Inventory, which was developed by Derogatis (1993) and adapted to Dutch by de Beurs (2004): somatization (e.g., "fainting and dizziness"), depression (e.g., "feeling lonely"), and hostility, because it included items referring to irritation and anger (e.g., "feeling angry and frustrated easily"). The number of items in the three subscales is seven, six, and five, respectively. Symptomatology during the previous week was recorded using a five-point scale from not at all (1) to extremely (5), $\alpha=.88$.

\section{Sociocultural Adaptation}

A 17-item measure of sociocultural adaptation was composed on the basis of Ward and Kennedy's (1999) definition and measurement of sojourners' adaptation. Adolescents indicated on a scale ranging from no difficulty (1) to extreme difficulty (5) the degree to which they experience difficulty in different domains of life (e.g., dealing with people in authority, making Belgian friends). Items were reverse coded so that high scores reflected better sociocultural adaptation $(\alpha=.90)$.

\section{Values}

Basic values were measured by 21 items which Schwartz (2003) developed for European Social Survey from the Portrait Values Questionnaire (Schwartz et al. 2001). Ten values included: Power, Achievement, Hedonism, Stimulation, Self-Direction, Universalism, Benevolence, Tradition, Conformity, and Security. Each value type was measured by two items, except for universalism (three items). The instrument contains short verbal portraits that describe a hypothetical person's goals, aspirations, or wishes that are thought to reflect the importance of a certain value type. Participants are asked to respond to each question "How much like you is this person?" on a scale of 1 (very much like me) to 5 (not like me at all). For the purposes of simplification, we reverse coded the items and formed indexes of four higherorder value orientations, as suggested by Schwartz (1992, 1994) and Schwartz and Boehnke (2004): self-enhancement (power, achievement), self-transcendence (universalism, benevolence), openness to change (self-direction, stimulation, hedonism), and conservatism (security, conformity, tradition). Because "the items in each index were selected to cover all components of the broad definition, rather than to measure a narrowly defined construct" (Schwartz et al. 2001, p. 532), the value indexes did not meet the "homogeneity" assumption of alpha. Schwartz and Boehnke (2004) assessed the structure of human values with data from 27 countries (including Turkey and Belgium) and validated the four higher-order value indexes.

\section{Perceived Discrimination}

Adolescents' perceptions of discrimination against themselves (person-level) and against their ethnic group (grouplevel) were measured. Person-level discrimination was assessed by asking adolescents the frequency of hostility or unfair treatment towards them in some public situations (e.g., in the street, in cafes or restaurants, at city hall). Group-level discrimination was measured by asking the adolescents if they think that Turks in Belgium experience hostility or unfair treatment in seven different situations (e.g., at school, at the workplace or when looking for work, in the street or when using public transport). Adolescents indicated their answers on five-point scales $(1=$ never, $5=$ frequently $), \alpha=.84$ for person-level discrimination and .87 for group-level discrimination.

\section{Results}

Prior to analyses, the distributions of the dependent variables were checked for normalcy and outliers (Tabachnick and Fidell 2001); no problems were detected. In addition, neither univariate nor multivariate outliers were found.

\section{Descriptive Statistics}

Table 1 displays descriptive statistics for the main measures. As shown by mean scores, heritage culture continuity in private life, followed by adaptation to the mainstream culture in public life, were most important to girls and boys alike. Adolescents valued self-transcendence most and selfenhancement least. Both psychological and sociocultural adaptation were relatively high, and perceived discrimination was relatively low, as indicated by scores above and below the relevant scale mid-points. Participants reported relatively higher discrimination against their ethnic group than against themselves personally.

\section{Gender and Age Comparisons}

\section{Analytical Plan}

The main goal of the present study was to explore gender differences and similarities in middle and late adolescence in a variety of acculturation-related variables. Preliminary examination of the zero-order correlation matrix revealed a pattern in which conceptually interrelated outcome variables were statistically and distinctively interrelated as well, 
Table 1 Descriptive statistics and tests of gender differences for the dependent variables.

\begin{tabular}{|c|c|c|c|c|c|c|}
\hline \multirow[t]{2}{*}{ Variables } & \multicolumn{2}{|c|}{ Girls $(n=96)$} & \multicolumn{2}{|c|}{ Boys $(n=103)$} & \multirow[t]{2}{*}{$F(d f)$} & \multirow[t]{2}{*}{$\eta^{2}$} \\
\hline & $M$ & $S D$ & $M$ & $S D$ & & \\
\hline \multicolumn{7}{|l|}{ Acculturation } \\
\hline Private culture maintenance & 4.26 & .80 & 4.49 & .71 & $3.73(1,193)$ & .02 \\
\hline Public culture maintenance & 3.45 & 1.06 & 3.60 & 1.09 & $.47(1,191$ & .00 \\
\hline Private culture adaptation & 3.01 & 1.25 & 2.82 & 1.26 & $.15(1,191)$ & .00 \\
\hline Public culture adaptation & 3.91 & .91 & 3.70 & 1.07 & $.90(1,192)$ & .01 \\
\hline \multicolumn{7}{|l|}{ Values } \\
\hline Self-enhancement & 2.88 & .65 & 3.16 & .77 & $16.19^{* *}(1,191)$ & .08 \\
\hline Self-transcendence & 3.79 & .70 & 3.75 & .67 & $.03(1,191)$ & .00 \\
\hline Openness to change & 3.67 & .71 & 3.59 & .69 & $.17(1,192)$ & .00 \\
\hline Conservatism & 3.35 & .70 & 3.54 & .71 & $4.36^{*}(1,191)$ & .02 \\
\hline \multicolumn{7}{|l|}{ Psychological adaptation } \\
\hline Self-esteem & 3.91 & .62 & 3.73 & .67 & $1.38(1,172)$ & .01 \\
\hline Symptomology & 2.13 & .61 & 2.06 & .64 & $1.51(1,172)$ & .01 \\
\hline Sociocultural adaptation & 4.08 & .54 & 3.83 & .69 & $6.08 *(1,172)$ & .04 \\
\hline \multicolumn{7}{|l|}{ Perceived discrimination } \\
\hline Person level & 1.75 & .82 & 2.33 & .96 & $15.41 * *(1,185)$ & .08 \\
\hline Group level & 2.65 & .89 & 2.64 & .90 & $.32(1,185)$ & .00 \\
\hline
\end{tabular}

All variables were assessed on scales from 1 to 5, with higher scores reflecting high degrees of the measured attribute. Gender differences on acculturation, values, and adaptation variables were tested by univariate $F$-tests that followed 2 (Gender) $\times 2$ (Age groups) MANOVAs. For perceived person- and group-level discrimination, gender differences were tested via individual univariate $F$-tests.

$* p<.05 ; * * p<.01$

as expressed by significant associations that were relatively high in number and generally moderate in magnitude (correlation matrix is available upon request from the first author). Therefore, gender and age differences were first detected by a series of 2 (Gender) $\times 2$ (Age groups) multivariate analysis of variance (MANOVA) with groups of four acculturation orientations, four value orientations, and three adaptation variables, followed by univariate $F$ tests. The Pillai-Bartlett Trace, a robust statistic for estimating a multivariate effect when the assumption of equal variance-covariance matrices for all groups was violated, was used in all multivariate tests. The correlation between perceived discrimination at the person and group levels was high $(r=.53)$. Given that high correlations between dependent variables introduce variable redundancy and can reduce statistical power (Ramsey 1982), effects on these variables were investigated individually via 2 (Gender) $\times 2$ (Age groups) ANOVAs.

\section{Acculturation}

No significant multivariate main effects were found; however, a Gender by Age interaction emerged, $F(4,187)=$ 2.76, $p<.05$, multivariate effect size (multi $\left.\eta^{2}\right)=.06$. Univariate tests suggested significant interactions in terms of adaptation to mainstream culture in the private and public spheres, $F \mathrm{~s}(1,190)=7.94$ and $5.70, p \mathrm{~s}<.05, \eta^{2}=.04$ and .03 , respectively. Older adolescent girls $(M=3.28, S D=$
1.18) reported greater adaptation to the mainstream culture in their private life than did middle adolescent girls $(M=$ 2.60, $S D=1.26)$ and older adolescent boys $(M=2.71, S D=$ 1.32). In addition, older adolescent girls $(M=4.18, S D=.78)$ attributed greater importance to adaptation in public in comparison with middle adolescent girls $(M=3.50, S D=95)$ and older adolescent boys $(M=3.71, S D=1.14)$.

Results indicated a significant main effect of age for acculturation orientations, $F(4,187)=3.70, p<.05$, multi $\eta^{2}=.07$. Post-hoc univariate tests indicated group differences in private culture maintenance and public culture adaptation, $F_{\mathrm{S}}(1,190)=5.25$ and 5.49 , respectively, $p<.05, \eta^{2}=.03$. Maintaining the culture of origin at home was more important to older adolescents $(M=4.48, S D=.73)$ than to middle adolescents $(M=4.23, S D=.80)$. At the same time, adaptation to the mainstream culture in the public sphere was more important to older adolescents $(M=3.93, S D=1.01)$ than to middle adolescents $(M=3.59, S D=.95)$.

\section{Values}

A MANOVA with the four value orientations (selfenhancement, self-transcendence, openness to change, and conservatism) revealed significant differences between girls and boys, $F(4,188)=6.45, p<.05$, multi $\eta^{2}=.12$; and between middle and late adolescents, $F(4,188)=3.23, p<.05$, multi $\eta^{2}=.06$. Univariate $F$-tests indicated both gender and age differences for self-enhancement values, $F \mathrm{~s}(1,191)=16.19$ 
and $6.89, p \mathrm{~s}<.05$ and .03 , respectively, and for conservatism values, $F_{\mathrm{s}}(1,191)=4.36$ and $6.36, p_{\mathrm{s}}<.05, \eta^{2}=.02$ and .03 , respectively. As seen in Table 1 , boys attributed greater importance to self-enhancement and conservatism values than did girls. In addition, older adolescents' ratings on selfenhancement and conservatism values $(M \mathrm{~s}=3.08,3.55, S D \mathrm{~s}=$ $.76, .73$, respectively) were higher than those of middle adolescents $(M \mathrm{~s}=2.80,3.28, S D \mathrm{~s}=.67, .65$, respectively).

Consistent with expectations, gender and age groups did not differ significantly in terms of self-transcendence and openness to change values, nor did a multivariate significant interaction effect emerge for overall value orientations.

\section{Adaptation}

A MANOVA examining self-esteem, symptomology, and sociocultural adaptation revealed a significant main effect of gender, $F(3,170)=4.00, p<.05$, multi $\eta^{2}=.07$, and a Gender by Age interaction, $F(3,170)=3.15, p<.05$, multi $\eta^{2}=.05$. The main effect of age was nonsignificant. As shown in Table 1, the gender difference emerged for sociocultural adaptation. As expected, girls reported better adaptation than boys $(M \mathrm{~s}=4.08,3.83, S D \mathrm{~s}=.54, .69$, respectively $), F(1$, $172)=6.08, p<.05, \eta^{2}=.04$. The univariate $F$-tests showed there were significant interaction effects for self-esteem and symptomology, $F \mathrm{~s}(1,172)=6.41$ and 5.06, $p \mathrm{~s}<.05, \eta^{2}=.04$ and .03 , respectively. Older adolescent girls reported higher self-esteem than did older adolescent boys and middle adolescent girls $(M \mathrm{~s}=4.09,3.72,3.65, S D \mathrm{~s}=.54, .76, .65$, respectively). Girls in middle adolescence reported more frequent symptomology than did boys in middle adolescence $(M \mathrm{~s}=2.24$ and $1.88, S D \mathrm{~s}=.78$ and .50 , respectively), but there was no difference between older adolescent girls' and boys' self-reported frequency of symptomology.

\section{Perceived Discrimination}

The main effect of gender was significant in perceived person-level discrimination (Table 1). As expected, boys reported more discrimination than did girls.

With regard to experiences of discrimination as a group, there was a significant main effect of age, $F(1,185)=4.27$, $p<.05, \eta^{2}=.02$, as well as a significant interaction between Gender and Age, $F(1,185)=4.16, p<.05, \eta^{2}=.02$. Older boys perceived more discrimination against their ethnic group than did younger boys $(M \mathrm{~s}=2.84,2.30, S D \mathrm{~s}=.78$, .89 , respectively).

\section{Discussion}

In the present study, we investigated the joint impact of two critical but relatively neglected factors in the field of psychology of immigrant adolescents - gender and development (Bornstein and Cote 2006; Suárez-Orozco and Qin 2006) — on acculturation, adaptation, values, and perceived discrimination among Turk heritage youth born and living in Belgium. The findings suggested that girls and boys agree in their positive attitudes toward their heritage culture and willingness to maintain it in their private life, but they tend to disagree in their endorsement of the mainstream culture in their public life and the way they perceived intercultural relationships. Notably, the gender gap became more salient in late adolescence.

\section{Gender}

Overall, Turk-heritage adolescent girls and boys assigned the same priority to maintaining their heritage culture in private life but preferred to adapt to the mainstream Belgian culture in public life, as expressed by average scores on each acculturation orientation. Reporting a similar pattern of acculturation among Turk immigrant youth in Belgium, Phalet and Hagendoorn (1996) and Phalet and Swyngedouw (2004) argued that Turk migrant adolescents achieve a good person-environment fit and adaptation by meeting the different expectations of their social communities. However, a closer look revealed gendered acculturation in private and public life. Confirming our expectations, adolescent girls appeared to adapt more than boys. More precisely, girls and boys did not differ in maintaining their heritage culture in their private and public lives, but older girls reported higher proficiency in the mainstream language and being more "Belgian" in both their private and public stances than older boys. Furthermore, older girls reported greater selfesteem than younger girls and older boys. Although younger boys reported less psychological distress (fainting and dizziness, feelings of loneliness, anger and frustration) than younger girls, girls seem to close the gap in late adolescence reporting similarly low levels of distress as boys. Furthermore, regardless of age, adolescent girls were better adapted in the sociocultural domain than adolescent boys.

By contrast, Turk heritage boys born and growing up in Belgium were more conservative and attached higher importance to self-enhancement, and thus to self-interest, social status, and prestige. Because previous studies did not report lower achievement aspirations among girls than among boys in spite of higher parental aspirations for sons in Turk migrant families (Phalet and Schönpflug 2001b), we did not expect girls and boys to differ in endorsing selfenhancement values. However, our measure of selfenhancement included achievement and power value; therefore, the greater value attached to self-enhancement among boys might reflect persisting uneven power relations in the traditional Turkish family where higher status is ascribed to the male line (Kagitcibasi 1970). It is widely 
recognized that migration challenges traditional power relations, which often results in the loss of status and disempowerment of men at home and at work (Pessar and Mahler 2003; Suárez-Orozco and Qin 2006). A common response on the male side is to accentuate male authority (Timmerman 2000). However, increased self-enhancement in late adolescence for boys and girls implies that acculturation empowers girls. In the transition from middle to late adolescence they appear to develop an awareness of opportunities in their new country, and thus become more appreciative of obtaining power, respect, and social status.

Boys reported more discrimination against themselves than did girls. This finding is parallel to past studies indicating that Turk immigrant men in Belgium are frequent targets of racism (Timmerman 1999). Moreover, older adolescent boys reportedly felt greater discrimination against Turks as a group than did girls or younger adolescent boys. Phinney (1989) reported enhanced ethnic exploration in middle adolescent immigrant youth, through which she supposed they develop a sense of belonging and increased ethnic identification. In combination with a stronger ethnic identification among Turk immigrant boys as compared to girls (Verkuyten 2002), hence, one might argue that, as they reach late adolescence, immigrant boys might be more aware of (or sensitive to) discrimination.

Being a target of discrimination is an intense emotional experience that calls forth effective coping mechanisms. Heightened collectivism can be one strategy that might explain the co-existence of conservatism and discrimination we found among boys. Collectivism has been found to be positively correlated with higher perceived and received support, less loneliness (Fijneman et al. 1996; Triandis et al. 1985), and less acculturative stress (Güngör 2007; Phalet and Hagendoorn 1996). Despite perceiving more discrimination, boys did not report higher symptomology, confirming past studies (e.g., Liebkind and Jasinskaja-Lahti 2000), but their self-esteem was lower than that of girls. Supposedly, immigrant boys use their social support network effectively to deal with acculturative stress on a daily basis. Nevertheless, the impact of negative intercultural experiences might be more evident on their global self-esteem. Consistent with this argument, Suárez-Orozco (2000) claimed that, in adolescence when formation of a coherent identity is a major developmental task, consistent exposure to distorted images and negative stereotypes from the multiple sources in one's adoptive society may make it difficult for immigrant youth to achieve and sustain a positive sense of self-worth. In light of these findings, it is crucial for future studies and interventions to recognize that well-being and self-esteem are two distinct components of psychological adaptation; therefore, they should be dealt with separately in terms of antecedents and short- and longterm consequences for acculturating youth.
Development in Adolescence

We divided the samples into middle (range $=14-17$ years) versus late (range $=18-20$ years) adolescent groups. In general, younger Turk heritage adolescents (particularly girls) born and growing up in Belgium admitted more symptoms than did older adolescents. By contrast, older adolescents reported adhering to their heritage culture more at home but showed greater adherence to Belgian culture in public. Overall, older adolescents held more conservative values than younger adolescents. Enculturation, the impact of culture on development, tends to be stronger in late adolescence than in earlier years of life as adolescents' lifestyles extend to include the social environment beyond their family (Kwak 2003). The socialization of acculturating youth occurs in multiple worlds, and thus requires constant negotiation of different norms and expectations of those worlds. The developmental shift from weaker to stronger endorsement of the culture of destination in public and of the culture of origin in private signifies a process of selective enculturation among Turk migrant youth. This situation underscores the necessity of adding a developmental perspective when studying adolescent acculturation.

A compelling contradiction emerged from this study in terms of openness to change and universalism on the one hand and heritage culture maintenance in public on the other. At the same time that middle and late adolescent Turk girls and boys alike reported being equally open to change and connected to others, all groups by age and gender tended to maintain their Turk culture in public equally. It seems that Belgium qua a western European county is missing an opportunity to integrate the immigrant Turk adolescents in its midst even when those adolescents are open to change and willing to relate across the board.

\section{Strengths and Limitations}

Most of the measures we studied report about subjective psychological states, and so could be assailed by a criticism of their shared source variance. Such intrapsychic states can be assessed either directly or indirectly. Indirect assessments might derive from observed behaviors or others' perceptions; direct assessments (our interest here) must derive from self-reports. Verbal reports of mental activity constitute an essential form of data in many areas of cognitive science (Ericsson and Simon 1993). In this study, we made direct assessments of adolescents' acculturation, values, adaptation, and discrimination using specific and theoretically based, self-report instruments. Moreover, much previous research in acculturation has focused on broad constructs and has confounded acculturation per se with other factors, such as social class and child age, thereby obscuring interpretations. The present study begins 
to address these several shortcomings by targeting specific and key constructs of adolescence, by approaching acculturation in adolescence from a multivariate stance, and by articulating specific expected hypotheses.

\section{Conclusions}

The findings of the present study point to some divergent paths of acculturation for adolescent girls and boys. In an acculturation context where the mainstream society offers a variety of options for girls as well as for boys, girls seem to take greater advantage by adopting mainstream culture values more readily. That said, maintaining their culture of origin was as important to girls as it was to boys. Boys are open to change and to relationships with others as are girls, but negative intercultural experiences seem to impede their adaptation and global feelings of self-worth.

Our study raises some critical next questions: Do girls persist in the empowering experience of acculturation, or is the acculturative shift only temporary and thus specific to a particular phase of development? What are the consequences of the gender gap in acculturation of girls and boys for their current and future relationships with one another, for intergenerational relationships in their families, and for their interactions with peers and others in the mainstream society? To address these questions, future studies should devote special attention to gender and developmental aspects of acculturation simultaneously. This approach would assist those working with immigrant youth to better understand gender-specific pathways of development in migration and acculturation and to design strategies for assistance, support, and intervention that promise to render acculturation a more positive experience for immigrant youth.

Acknowledgements This research was supported by the Intramural Research Program of the NIH, NICHD and the Migration Research Program at Koc University (MiReKoc), Istanbul, Turkey. The manuscript was prepared during the EU Marie Curie International Fellowship awarded to the first author. Special thanks to Karen Phalet, Maurice Haynes, and Diane Putnick for their contribution at the different stages of the study.

Open Access This article is distributed under the terms of the Creative Commons Attribution Noncommercial License which permits any noncommercial use, distribution, and reproduction in any medium, provided the original author(s) and source are credited.

\section{References}

Abadan-Unat, N. (2002). Bitmeyen göç: Konuk ișçilikten ulus-ötesi yurttaşlı̆̆a. [Unfinished migration: From being guest-worker to transnational citizenship]. İstanbul: Bilgi University.
Arends-Toth, J., \& Van de Vijver, F. J. R. (2003). Multiculturatilsm and acculturation: Views of Dutch and Turkish-Dutch. European Journal of Social Psychology, 33, 249-266.

Arends-Toth, J., \& Van de Vijver, F. J. R. (2006). Issues in conceptualization and assessment of acculturation. In M. H. Bornstein, \& L. R. Cote (Eds.), Acculturation and parent-child relationships: Measurement and development (pp. 33-62). Mahwah: Erlbaum.

Arrindell, W. A., Sanavio, E., Aguilar, G., Sica, C., Hatzichristou, C., et al. (1999). The development of a short form of the EMBU: Its appraisal with students in Greece, Guatemala, Hungary and Italy. Personality and Individual Differences, 27, 613-628.

Berry, J. W. (1980). Acculturation as varieties of adaptation. In A. Padilla (Ed.), Acculturation: Theory, models and findings (pp. 925). Boulder, CO: Westview.

Berry, J. W. (1997). Immigration, acculturation, and adaptation. Applied Psychology: An International Review, 46, 5-68.

Berry, J. W. (2003). Conceptual approaches to acculturation. In K. Chun, P. Balls-Organista, \& G. Marin (Eds.), Acculturation: Advances in theory, measurement and applied research (pp. 1737). Washington, DC: APA.

Berry, J. W., \& Kalin, R. (1995). Multicultural and ethnic attitudes in Canada. Canadian Journal of Behavioural Science, 27, 310-320.

Berry, J. W., Phinney, J. S., Sam, D. L., \& Vedder, P. (2006). Immigrant youth: Acculturation, identity, and adaptation. Applied Psychology: An International Review, 55, 303-332.

Berry, J. W., \& Sam, D. L. (1997). Acculturation and adaptation. In J. W. Berry, M. H. Segall, \& C. Kagitcibasi (Eds.), Handbook of cross-cultural psychology, vol. 3, social behavior and applications (pp. 291-326). Boston: Allyn and Bacon.

Bornstein, M. H., \& Cote, L. C. (Eds.) (2006). Acculturation and parent child relationships: Measurement and development. Mahwah, NJ: Erlbaum.

Bornstein, M. H., Hahn, C.-S., \& Haynes, O. M. (2004). Specific and general language performance across early childhood: Stability and gender considerations. First Language, 24, 267-304.

Brislin, R. W. (1980). Translation and content analysis of oral and written material. In H. C. Triandis, \& J. W. Berry (Eds.), Handbook of cross-cultural psychology (vol. 1, pp. 389-444). Boston: Allyn and Bacon.

Brislin, R. W. (1986). The wording and translation of research instruments. In W. J. Lonner, \& J. W. Berry (Eds.), Field methods in cross-cultural research (pp. 137-164). Newbury Park, CA: Sage.

de Beurs, E. (2004). Brief Symptom Inventory, handleiding. Leiden: the Netherlands.

Derogatis, L. R. (1993). BSI Brief Symptom Inventory: Administration, scoring, and procedures manual (4th ed.). Minneapolis, MN: National Computer Systems.

Dion, K. L. (2001). The social psychology of perceived prejudice and discrimination. Canadian Psychology, 43, 1-10.

Ericsson, K. A., \& Simon, H. A. (1993). Protocol analysis: Verbal report as data (Rev. ed.). Cambridge, MA: Bradford Books.

Fijneman, Y. A., Willemsen, M. E., \& Poortinga, Y. H. (1996). Individualism-collectivism: An empirical study of a conceptual issue. Journal of Cross-Cultural Psychology, 27, 381-402.

Fuligni, A. (2001). A comparative longitudinal approach to acculturation among children from immigrant families. Harvard Educational Review, 71, 566-578.

Gurr, T. R., \& Harff, B. (1994). Ethnic conflict in world politics. Colorado: Westview.

Güngör, D. (2007). The interplay between values, acculturation and adaptation: A study on Turkish-Belgian adolescents. International Journal of Psychology, 42, 380-392.

Hagendoorn, L. (1995). Intergroup biases in multiple group systems: The perception of ethnic hierarchies. In W. Stroebe, \& M. Hewstone (Eds.), European review of social psychology (pp. 199-228). Chichester, UK: Wiley. 
Hernandez, D. J., \& Charney, E. (Eds.) (1998). From generation to generation: The health and well-being of children in immigrant families. Washington, DC: National Academy Press.

Hernandez, D. J., Denton, N. A., \& Macartney, S. E. (2008). Children in immigrant families: looking to America's future. Society for Research in Child Development Social Policy Report, 22(3), 322.

Hrubes, D., Ajzen, I., \& Daigle, J. (2001). Predicting hunting intentions and behavior: An application of the theory of planned behavior. Leisure Sciences, 23, 165-178.

Idema, H., \& Phalet, K. (2007). Transmission of gender-role values in Turkish-German migrant families: The role of gender, intergenerational and intercultural relations. Zeitschrift für Familienforschung, 19, 71-105.

Jasinskaja-Lahti, I., \& Liebkind, K. (2001). Perceived discrimination and psychological adjustment among Russian-speaking immigrant adolescents in Finland. International Journal of Psychology, 36, 174-185.

Kağıtçıbaşı, Ç. (1970). Social norms and authoritarianism: A TurkishAmerican comparison. Journal of Personality and Social Psychology, 16, 444-451.

Kağıtçıbașı, Ç. (2007). Family, self, and human development: Theory and application (2nd ed.). Mahwah, NJ: Erlbaum.

Kwak, K. (2003). Adolescents and their parents: A review of intergenerational family relations for immigrant and non-immigrant families. Human Development, 46, 115-136.

Lange, A. L. (1990). Ethnic/national identification, stereotypes and perceptions of cultural differences. European Journal of Social Science, 3(4), 589-655.

Lansford, J., Deater-Deckard, K. K., \& Bornstein, M. H. (Eds.) (2007). Immigrant families in contemporary society. New York: Guilford.

Lebedeva, N., \& Tatarko, A. (2004). Socio-psychological factors of ethnic intolerance in Russia's multicultural regions. In B. Setiadi, A. Supratiknya, W. Lonner, \& Y. Poordinga (Eds.), Ongoing themes in psychology and culture. Selected papers from the Sixteenth International Congress of the International Association for Cross-Cultural Psychology (pp. 507-532). Jakarta: Indonesian Universities Press.

Liebkind, K., \& Jasinskaja-Lahti, I. (2000). The influence of experiences of discrimination on psychological stress: A comparison of seven immigrant groups. Journal of Community and Applied Psychology, 10, 1-16.

Moghaddam, F. M., Ditto, B., \& Taylor, D. M. (1990). Attitudes and attributions related to psychological symptomatology in Indian women. Journal of Cross-Cultural Psychology, 21,335350 .

Motti-Stefanidi, F. (2008). The role of immigrant children for the economic development and the social cohesion of our societies: A European perspective. Society for Research in Child Development Social Policy Report, 22(3), 14-15.

Pessar, P. R., \& Mahler, S. J. (2003). Transnational migration: Bringing gender in. The International Migration Review, 37, 812-846.

Phalet, K., \& Hagendoorn, L. (1996). Personal adjustment to acculturative transitions: The Turkish experience. International Journal of Psychology, 31, 131-144.

Phalet, K., \& Haker, F. (2004). Moslim in Nederland. Deel II: Religie, familiewaarden en binding [Muslim in the Netherlands: part II: Religion, family values and ties] (pp. 43-61). The Hague: SCP.

Phalet, K., \& Schönpflug, U. (2001a). Intergenerational transmission of collectivism and achievement values in two acculturation contexts: The case of Turkish families in Germany and Turkish and Moroccan families in the Netherlands. Journal of CrossCultural Psychology, 32, 186-201.

Phalet, K., \& Schönpflug, U. (2001b). Intergenerational transmission in Turkish immigrant families: Parental collectivism, achieve- ment values and gender differences. Journal of Comparative Family Studies, 32, 489-504.

Phalet, K., \& Swyngedouw, M. (2004). A cross-cultural analysis of immigrant and host values and acculturation orientations. In $\mathrm{H}$. Vinken, J. Soeters, \& P. Ester (Eds.), Comparing cultures: Dimensions of culture in a comparative perspective (pp. 181208). Leiden: Brill.

Phinney, J. S. (1989). Stages of ethnic identity development in minority group adolescents. The Journal of Early Adolescence, 9 , 34-49.

Phinney, J. S. (1990). Ethnic identity in adolescents and adults: Review of research. Psychological Bulletin, 108, 499-514.

Phinney, J. S. (2006). Acculturation is not an independent variable: Approaches to studying acculturation as a complex process. In M. H. Bornstein, \& L. R. Cote (Eds.), Acculturation and parentchild relationships: Measurement and Development (pp. 79-95). Mahwah, NJ: Erlbaum.

Ramsey, P. H. (1982). Empirical power of procedures for comparing two groups on p variables. Journal of Educational Statistics, 7, 139-156.

Ros, M., Schwartz, S. H., \& Surkiss, S. (1999). Basic individual values, work values, and the meaning of work. Applied Psychology: An International Review, 48, 49-71.

Rosenberg, M. (1965). Society and the adolescent self-image. Princeton, NJ: Princeton University Press.

Ryder, A. G., Alden, L. E., \& Paulhus, D. R. (2000). Is acculturation unidimensional or bidimensional?: A head to head comparison in the prediction of personality, self-identity, and adjustment. Journal of Personality and Social Psychology, 79, 49-65.

Sam, D. (2000). Psychological adaptation of adolescents with immigrant backgrounds. The Journal of Social Psychology, 140, $5-25$.

Sam, D. L., Vedder, P., Ward, C., \& Horenczyk, G. (2006). Psychological and socio-cultural adaptation of immigrant youth. In J. W. Berry, J. S. Phinney, D. L. Sam, \& P. Vedder (Eds.), Immigrant youth in cultural transition: Acculturation identity and adaptation across national contexts (pp. 117-141). Mahwah, NJ: Erlbaum.

Schönpflug, U. (2001). Intergenerational transmission of values: The role of transmission belts. Journal of Cross-Cultural Psychology, $32,174-185$.

Schwartz, S. H. (1992). Universals in the content and structure of values: Theoretical advances and empirical tests in 20 countries. In M. Zanna (Ed.), Advances in experimental social psychology (vol. 25, pp. 1-65). New York: Academic.

Schwartz, S. H. (1994). Are there universal aspects in the content and structure of values. The Journal of Social Issues, 50, 19-45.

Schwartz, S. H. (2003). A proposal for measuring value orientations across nations [Chapter 7 in the Questionnaire Development Report of the European Social Survey]. Retrieved May 10, 2006, from http://www.europeansocialsurvey.org/index. php?option $=$ com_docmanandtask $=$ doc_viewandgid $=126$ andite $\operatorname{mid}=80$

Schwartz, S. H., \& Bilsky, W. (1990). Toward a universal theory of the content and structure of values. Journal of Personality and Social Psychology, 58, 878-891.

Schwartz, S. H., \& Boehnke, K. (2004). Evaluating the structure of human values with confirmatory factor analysis. Journal of Research in Personality, 38, 230-255.

Schwartz, S. H., Melech, G., Lehmann, A., Burgess, S., \& Harris, M. (2001). Extending the cross-cultural validity of the theory of basic human values with a different method of measurement. Journal of Cross-Cultural Psychology, 32, 519-542.

Smila, M. (1987). Cultural identity in young immigrants: A study of sociocultural conditions and ethnic identification among Turks and Yugoslavs in Stockholm (Rep. No. 7). Stockholm, Sweden: 
University of Stockholm, Center for Research in International Migration and Ethnic Relations.

Suárez-Orozco, C. (2000). Identities under siege: Immigration stress and social mirroring among the children of immigrants. In A. Robben, \& M. Suárez-Orozco (Eds.), Cultures under siege: Social violence \& trauma (pp. 194-226). Cambridge: Cambridge University Press.

Suárez-Orozco, C., \& Qin, D. B. (2006). Gendered perspectives in psychology: Immigrant origin youth. The International Migration Review, 40, 165-198.

Tabachnick, B., \& Fidell, L. (2001). Using multivariate statistics (4th ed.). New York: Harper and Row.

Taylor, D. M., Wright, S. C., Moghaddam, F. M., \& Lalonde, R. N. (1990). The personal/ group discrimination discrepancy: Perceiving my group, but not myself, to be a target of discrimination. Personality and Social Psychology Bulletin, 16, 254-262.

Tielens, M. (2005). Eens allochtoon, altijd allochtoon?: De socioeconomische etnostratificatie in Vlaanderen [Once foreigner, always foreigner?: The socioeconomic ethnostratification in Flanders]. WAV-rapport, Leuven, Belgium. Retrieved March 30, 2008, from http://www.steunpuntwav.be/view/n1/155244? section $=$ samenvatting

Timmerman, C. (1999). Onderwijs maakt het verschil: Socio-culturele praxis en etniciteitsbeleving bij Turkse jonge vrouwen. Leuven, Belgium: ACCO.

Timmerman, C. (2000). Secular and religious nationalism among young Turkish women in Belgium: Education may make the difference. Anthropology and Education Quarterly, 31, 333354

Triandis, H., Leung, K., Villareal, M., \& Clack, F. (1985). Allocentric vs. idiocentric tendencies: Convergent and discriminant validation. Journal of Research in Personality, 19, 395-415.
Van Damme, J., Meyer, J., De Troy, A., \& Mertens, W. (2001). Succesvol middelbaar onderwijs? Een antwoord van het LOSOproject. Leuven: ACCO.

Van Oudenhouven, J. P., Willemsma, G., \& Prins, K. S. (1996). Integratie en assimilatie van Marokkanen, Surinamers en Turken in Nederland [Integration and assimilation of Moroccans, Surinamese, and Turks in the Netherlands]. Psycholoog, 31, 468-471.

Vedder, P., Sam, D. L., \& Liebkind, K. (2007). The acculturation and adaptation of Turkish adolescents in North-Western Europe. Applied Developmental Science, 11, 126-136.

Verhoeven, H. (2000). De vreemde eend in de bijt; arbeidsmarkt en diversiteit. WAV-dossier. Leuven.

Verkuyten, M. (2002). Perceptions of ethnic discrimination by minority and majority early adolescents in the Netherlands. International Journal of Psychology, 37, 321-332.

Verkuyten, M., \& Kinket, B. (2000). Social distances in a multiethnic society: The ethnic hierarchy among Dutch preadolescents. Social Psychology Quarterly, 63, 75-85.

Virta, E., Sam, D. L., \& Westin, C. (2004). Adolescents with Turkish background in Norway and Sweden: A comparative study of their psychological adaptation. Scandinavian Journal of Psychology, 45, 15-25.

Ward, C., Bochner, S., \& Furnham, A. (2001). The psychology of culture shock. London: Routledge.

Ward, C., \& Kennedy, A. (1994). Acculturation strategies, psychological adjustment, and sociocultural competence during crosscultural transitions. International Journal of Intercultural Relations, 18, 329-343.

Ward, C., \& Kennedy, A. (1999). The measurement of sociocultural adaptation. International Journal of Intercultural Relations, 23, 659-677. 